\title{
Characterisation of two unique unifloral honeys from the boreal coniferous zone: lingonberry and mire honeys
}

\author{
Anneli Salonen* and Riitta Julkunen-Tiitto \\ Natural Product Research Laboratories, Länsikatu 15, 80110 Joensuu, Finland, Department of Biology, University of \\ Eastern Finland. \\ e-mail: anneli.salonen@uef.fi
}

\begin{abstract}
Studies of unifloral honeys are rare in Finland, and thus there are no common traits accepted for their characterization. In our study lingonberry and mire honeys were characterized. The physico-chemical, organoleptic and melissopalynological properties and phenolic composition of the honeys were analysed and the floral origin of the mire honey was considered. Lingonberry honey was reddish and had a flavour of toffee, whereas mire honey had very strong aroma and reddish colour. Both honeys had high electrical conductivity and $\mathrm{pH}$ values when compared to Finnish polyfloral honeys. They were both rich in fructose, while the number of disaccharides in lingonberry honey was four and in mire honey six. Lingonberry honey had three unifloral specific phenolic compounds whereas mire honey had no unifloral-specific phenolic compounds, and its floral origin was not clearly defined.
\end{abstract}

Key words: unifloral honey, physico-chemical properties, phenolic compounds, melissopalynology

\section{Introduction}

Honey can be classified in several ways, e.g. by its source. The European Council Directive 2001/110/ EC concerning honey allows specific denominations of honeys where the simple product name "honey" can be supplemented by information on the floral, vegetable, regional, territorial or topographical origin (European Commission 2002). Thus, if the nectar from which the bees have derived the honey is gathered mainly from the flowers of one specific plant species in the foraging area of the beehive, the honey is called unifloral honey and it can be named after the plant from which the nectar originates (White 2005). On the other hand, the source of the honey may be the mixed flora of a specific biotope in the foraging area of the beehive, and in some cases this kind of honey may have a unique organoleptic nature due to amount and combination of various components specific to this honey. In these cases EU directive concerning honey allows the specific denomination, where the product name "honey" is supplemented by the information on the topographical origin. Well known examples of these kinds of honeys are jungle or pasture honeys (Fukuda et al. 2011). Unifloral and biotope honeys may have a special taste or consist of substances that are beneficial to human health, and this may often make their commercial value greater than that of multifloral honeys (Bogdanov et al. 2008).

In Finland, predominant forest types range from mesic nutrient rich to oligotrophic dry heath coniferous forests (Ahti et al. 1968) and about $30 \%$ of the land area is classified as mire ecotype (Vasander et al. 2003). In eastern and northern Finland the main honey yield comes from wild forest plants typical of boreal coniferous zone flora (Salonen et al. 2009). Under favourable weather conditions lingonberry (Vaccinium vitis-idaea), which is one of the most common berry plants in Finnish forests (Lampinen and Lahti 2011) can produce an adequate amount of nectar to build up a honey yield with a special aroma. Moreover,

Manuscript received February 2012 


\section{AGRICULTURAL AND FOOD SCIENCE}

A. Salonen \& R. Julkunen-Tiitto (2012) 21: 159-170

plant species growing in a mire biotope, such as several species of Vaccinium family, Rubus chamaemorus, Menyanthes trifoliata and Geranium sylvaticum can also produce a nectar yield that produces honey with a characteristic aroma. This honey is called mire honey.

In recent years, some Finnish beekeepers have started produce lingonberry honey and mire honey for commercial purposes in central, eastern and northern Finland (Lapland), and they have also been able to export both honeys at a good price. Therefore there is a commercial need to characterize these two unique honeys. The previous basic data on Finnish honey by Varis et al. (1983) gives very little information on the composition of unifloral honeys from the boreal coniferous forests. More detailed data on the properties of boreal unifloral honeys from raspberry and fireweed has been reported by Salonen et al. (2011). In this study, we investigated the physico-chemical values for Finnish lingonberry and mire honey and described here their sensorial properties and melissopalynology as well as the phenolic acids and flavonoids as a basis for distinguishing these two unifloral honeys from other Finnish unifloral and multifloral honeys. In addition, the botanical origin of the mire honey was considered.

\section{Material and methods}

\section{Honey samples}

Seven lingonberry and eight mire honey samples were collected in summer 2007 and 2008 with the help of the Finnish Beekeepers Association and Finnish beekeepers. All samples were from commercial honey batches. Honey samples were selected by those organoleptic characteristics that are typical of these two unifloral honeys (colour, taste and odour) in order to find truly representative samples. The honey samples were stored at $+5^{\circ} \mathrm{C}$ in the dark until analysis.

\section{Analyses of physical properties and invertase activity}

All physical properties and invertase activity were analysed following the analytical methods harmonized by the International Honey Commission (Bogdanov 2009). A digital refractometer was used for the determination of water content directly from the honey (Atago 4422 PAL-22S Digital Pocket Honey Refractometer). Conductivity was measured with a Multiline P4 Universal Meter from a $10 \mathrm{~g}$ dry matter in a dose of honey dissolved in $50 \mathrm{ml}$ of MilliQ water. The $10 \%$ honey-water solution was used in $\mathrm{pH}$-measurements using a PHM 210 standard pH Meter (Meter Lab Radiometer, Copenhagen). Invertase activity was determined by the methods published by Bogdanov (2009) and invertase activity is expressed as invertase number, which indicates the amount of sucrose $(\mathrm{g})$ in $100 \mathrm{~g}$ of honey hydrolysed for one hour by the invertase.

\section{Organoleptic properties}

The method presented by Piana et al. (2004) was used in the analyses of organoleptic properties. Visual, olfactory and taste characteristics were noted on an evaluation form.

\section{Sugar analyses}

The method for sugar has been described in Salonen et al. (2011). The $0.5 \%$ honey water-acetonitrile solution were eluted with isocratic $75 \%$ acetonitrile-water elution solvent $1.4 \mathrm{ml} / \mathrm{min}$ using the HighPerformance Liquid Chromatography-instrument (HPLC) (Agilent, Series 1100, Germany) containing a binary pump (G1316A), a thermostated autosampler (G1329A), a thermostated column oven (G1316A) and a refractive index detector (RID) (G1362A) combined with HP Chem Station Software. The column 


\section{AGRICULTURAL AND FOOD SCIENCE}

A. Salonen \& R. Julkunen-Tiitto (2012) 21: 159-170

was Zorbax, carbohydrate, $4.6 \times 150 \mathrm{~mm}$, particle size $5 \mu \mathrm{m}$. For the qualification and quantification of the saccharides the HPLC-chromatograms of the samples were compared to those of commercial standards. The standards were fructose, glucose, maltose (Merck), D-turanose, panose, erlose, melezitose, isomaltose (Sigma-Aldrich), gentiobiose, raffinose (Sigma), saccharose (VWR) and trehalose (ICN Biomedicalsinc)

\section{Melissopalynological analyses}

The qualitative melissopalynological characteristics of the honey samples were analysed according to Louveaux et al. (1987). At least 400 pollen grains were counted from a $10 \mathrm{~g}$ washed and centrifuged honey sample.

\section{Analyses of phenolic compounds}

Phenolic compounds were extracted and reversed phase HPLC analysed as published by Salonen et al. (2011). Phenolics in $25 \mathrm{~g}$ of honey were allowed to bind with amberlite XAD-2 resin in a separation funnel for ten minutes at room temperature, the acidified water was separated and the amberlite was washed with neutral water. The phenolic compounds were recovered with methanol. Before HPLC analysis, $5 \mathrm{ml}$ of water was added and the samples were extracted into $5 \mathrm{ml}$ diethyl ether. The ether was evaporated and the sample dissolved in methanol $(0.25 \mathrm{ml})$ and MilliQ water $(0.25 \mathrm{ml})$. Each honey sample was fractionated and analysed in duplicate. Phenolic compounds were analysed using an HPLC instrument (Agilent, Series 1100, Germany) containing a binary pump (G1316A), a thermostated autosampler (G1329A), a thermostated column oven (G1316A) and a Diode Array Detector (DAD) (G1315B) combined with HP Chem Station Software, as previously published by Salonen et al. (2011). The column was Zorbax, SB-C18, 4.6×75 mm, particle size3.5 $\mu \mathrm{m}$. $1.5 \%$ tetrahydrofuran $+0.25 \%$ ortho-phosphoric acid water $(=A)$ and $100 \%$ methanol $(=B)$ were the elution solvents. The samples were eluted according to the following gradient: $0-5 \min 100 \% A ; 5-10 \min 85 \% A$, $15 \%$ B; $10-20 \min 70 \%$ A, 30\% B; $20-50 \min 50 \%$ A, 50\% B; 50\% B; 50-55 min 100\% B. The flow rate was 2 $\mathrm{ml} \mathrm{min} \mathrm{m}^{-1}$ and the auto-injection volume was $20 \mu \mathrm{l}$. The temperatures of the column and injector were +30 and $+20^{\circ} \mathrm{C}$, respectively. The HPLC runs were monitored at 220 and $320 \mathrm{~nm}$.

The identification of phenolic compounds was based on a comparison of retention times and spectral characteristics of the HPLC/MS-identification of the MS-ions as described in Julkunen-Tiitto and Sorsa (2001) and Keski-Saari et al. (2005).

The quantification of phenolic compounds was based on the commercial standards: protocatechuic acid (Sigma-Aldrich) for protocatechuic acid; ferulic acid (Aldrich) for ferulic acid, cinnamic acid derivatives, p-OH-cinnamic acid derivatives and caffeic acid derivative; chlorogenic acid (Roth) for chlorogenic acid derivatives; vanillic acid (Fluka AG) for vanillic acid; benzoic acid (Sigma) for benzoic acid and benzoic acid derivatives; kaempferol 3-O-rhamnoside (Apin Chemicals Ltd) for kaempferol 3-O-rhamnoside; quercetin (Aldrich) for flavonoid derivative; isorhamnetin (Roth) for rhamnetin derivatives; galangin (Aldrich) for galangin derivatives; apigenin (Roth) for apigenin; naringenin7-glucoside (Roth) for methyl-naringenin; and acacetin for acacetin (Roth).

\section{Results Lingonberry honey}

The electrical conductivity of lingonberry honey was 0.5 milli Siemens $\mathrm{cm}^{-1}\left(\mathrm{mS} \mathrm{cm}^{-1}\right)$ and $\mathrm{pH} 4.5$. These results are markedly higher than those of the average Finnish polyfloral honeys. The water content was low and the invertase activity value high (Table 1). 


\section{AGRICULTURAL AND FOOD SCIENCE}

A. Salonen \& R. Julkunen-Tiitto (2012) 21: 159-170

Table 1. The physical parameters of lingonberry, mire and Finnish polyfloral honey samples.

\begin{tabular}{lllllllc}
\hline & \multicolumn{2}{l}{ Lingonberry honey } & & \multicolumn{2}{l}{ Mire honey } & \multicolumn{3}{l}{ Finnish polyfloral honey } \\
\hline Parameter & $\mathrm{n}$ & Mean $\pm \mathrm{SE}$ & $\mathrm{n}$ & Mean $\pm \mathrm{SE}$ & $\mathrm{n}$ & Mean & Range \\
\hline Moisture (\%) & 7 & $16.6 \pm 0.5$ & 8 & $16.6 \pm 0.3$ & 1151 & $16.9^{* *}$ & $13.2-21.6$ \\
Conductivity (mS cm-1 ) & 7 & $0.5 \pm 0.76$ & 8 & $1.08 \pm 0.33$ & 1151 & $0.27^{* *}$ & $0.1-1.88$ \\
$\mathrm{pH}$ & 7 & $4.5 \pm 0.1$ & 8 & $4.9 \pm 0.1$ & 158 & $4.0^{*}$ & $3.6-4.6$ \\
Invertase activity & 6 & $150 \pm 14.2$ & 5 & $145.4 \pm 16.4$ & 1151 & $92.5^{* *}$ & $9-267$ \\
\hline
\end{tabular}

SE $=$ standard error of the mean.

* Reference: Varis et al. 1983, ** Reference: Sample material described in Salonen et al. 2009.

In sensorial analysis the colour of lingonberry honey had a dark intensity and reddish tone. The intensity of odour was medium and the descriptions of the odour were "resinous, dry hay, toffee, fresh, orange, cedar, pungent and apricot". The sweetness assessments varied from weak to strong. Acidity of the honey was medium and bitterness weak. The intensity of the aroma was medium and the descriptions were "toffee, citrus fruit, candied fruits, fruits and exotic fruit". The persistence or after-taste value was between short and medium.

Lingonberry honey was rich in fructose and its fructose/glucose ratio was over 1.4 and glucose/water ratio 1.7 (Table 2), suggesting that this honey granulates slowly. All the samples contained the disaccharides sucrose, turanose, maltose or trehalose (peaks overlapping) and isomaltose. In addition, lingonberry honey contained oligosaccharides (erlose or melezitose, peaks overlapping). However, the disaccharides maltose and trehalose and the two oligosaccharides erlose and melezitose could not be separated with the novel carbohydrate column used because the peaks overlapped.

Table 2. Composition of mono-, di- and oligosaccharides, fructose/glucose and glucose/water ratios and total amount of monosaccharides in lingonberry and mire honey samples.

\begin{tabular}{|c|c|c|c|c|c|c|c|}
\hline \multirow[t]{2}{*}{ Compound } & \multicolumn{2}{|c|}{ Lingonberry honey } & \multicolumn{2}{|c|}{ Mire honey } & \multicolumn{3}{|c|}{ Finnish polyfloral honey } \\
\hline & $\mathrm{n}$ & Mean \pm SE & $\mathrm{n}$ & Mean \pm SE & $\mathrm{n}$ & Mean & Range \\
\hline Fructose (g 100 g-1) & 7 & $40.3 \pm 0.8$ & 8 & $39.2 \pm 0.41$ & 158 & $47.3 * * *$ & $38.5-58.4$ \\
\hline Glucose (g 100 g-1) & 7 & $27.7 \pm 1.5$ & 8 & $28.2 \pm 0.34$ & 158 & $43.9 * * *$ & $34.3-54.5$ \\
\hline Saccharose (g 100 g-1) & 6 & $0.26 \pm 0.11$ & 6 & $0.11 \pm 0.03$ & & & \\
\hline Turanose (g 100 g-1) & 6 & $2.22 \pm 0.10$ & 6 & $2.79 \pm 0.11$ & & & \\
\hline Unknown 1 & 6 & 0 & 6 & peak & & & \\
\hline Unknown 2 & 6 & 0 & 6 & peak & & & \\
\hline Maltose/Trehalose (g $100 \mathrm{~g}-1)^{*}$ & 6 & $1.11 \pm 0.09$ & 6 & $1.35 \pm 0.09$ & & & \\
\hline Isomaltose (g $100 \mathrm{~g}-1)$ & 6 & $2.17 \pm 0.16$ & 6 & $2.56 \pm 0.15$ & & & \\
\hline Gentiobiose (g 100 g-1) & 6 & 0 & 6 & 0 & & & \\
\hline Melezitose/ Erlose (g 100 g-1)** & 6 & $0.53 \pm 0.10$ & 6 & $0.69 \pm 0.04$ & & & \\
\hline Raffinose (g 100 g-1) & 6 & 0 & 6 & peak & & & \\
\hline Panose (g 100 g-1) & 6 & 0 & 6 & 0 & & & \\
\hline Fructose/Glucose ratio & 7 & $1.48 \pm 0.07$ & 8 & $1.39 \pm 0.02$ & 158 & 1.1 & \\
\hline Glucose/Water ratio & 7 & $1.68 \pm 0.11$ & 8 & $1.70 \pm 0.03$ & & & \\
\hline Fructose+Glucose (g 100 g-1) & 7 & $68.0 \pm 2.24$ & 8 & $67.4 \pm 0.49$ & & & \\
\hline
\end{tabular}

$\mathrm{SE}=$ standard error of the mean

* Peaks overlapping, calculated as trehalose, ${ }^{* *}$ Peaks overlapping, calculated as melezitose, ${ }^{* * *}$ Reference: (Varis et al. 1983).

Method: thin layer chromatography. 


\section{AGRICULTURAL AND FOOD SCIENCE}

A. Salonen \& R. Julkunen-Tiitto (2012) 21: 159-170

We identified eighteen different phenolic compounds in the samples of lingonberry honey (Fig. 1): seven cinnamic acid derivatives and flavonoids, benzoic, vanillic and protocatechuic acids and tetragalloylglucose (Table 3). The most abundant were vanillic and benzoic acids. The amount of flavonoids was very low, only $0.57 \mu \mathrm{g} \mathrm{g}^{-1}$, and the ratio of phenolic acids to flavonoids was 19.5. Phenolic compounds typical for lingonberry honey samples were cinnamic acid derivative 1 (retention time, $t_{R} 3.1$ ), p-OH-cinnamic acid derivative $2\left(t_{R} 23.9\right)$ and acacetin ( $\left.t_{R} 44.1\right)$ (Fig. 1).

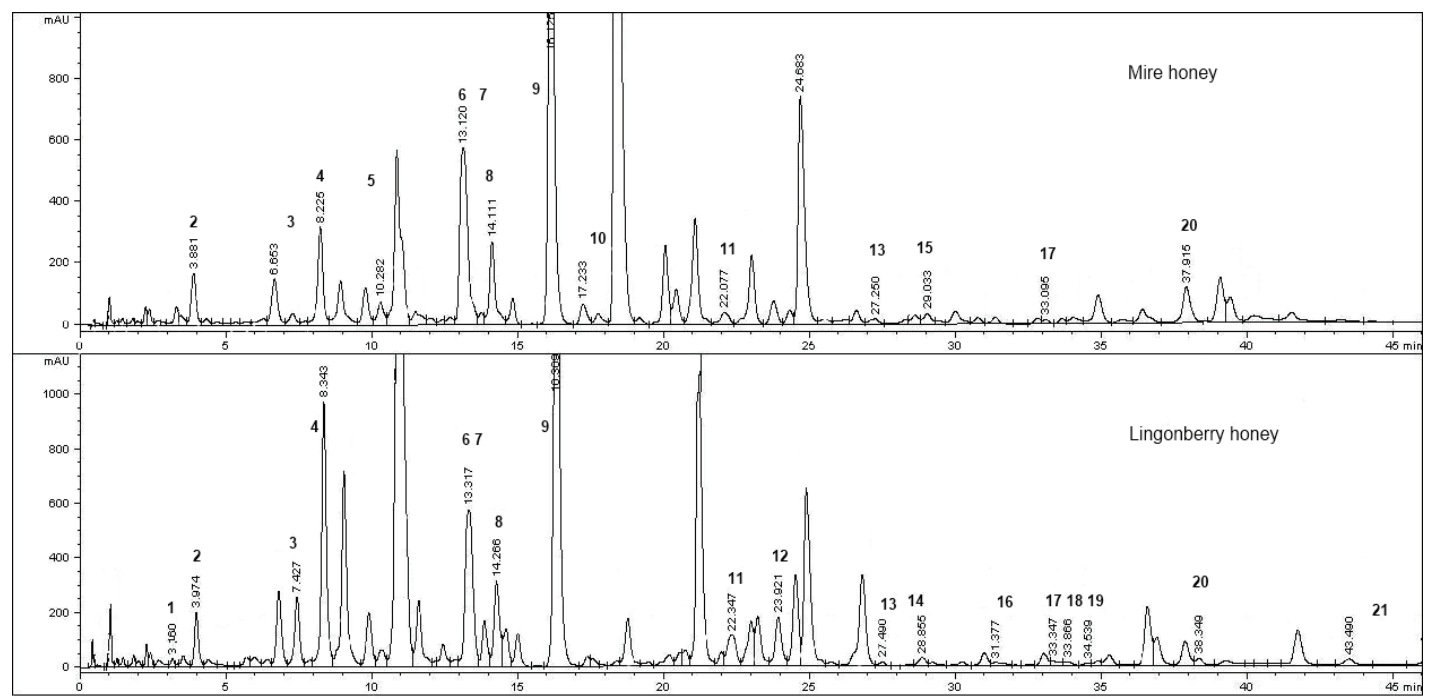

Fig. 1. HPLC chromatograms (DA-detection, monitored at $220 \mathrm{~nm}$ ) of the mire and lingonberry honey samples. $1 \mathrm{Cin}-$ namic acid der 1, 2 Protocatechuic acid, 3 Cinnamic acid der 2, 4 Vanillic acid, 5 Chlorogenic acid der , 6 p-OH-cinnamic acid der 1, 7 Benzoic acid, 8 Ferulic acid, 9 Tetragalloylglucose, 10 Benzoic acid der, 11 Cinnamic acid der 3, 12 p-OHcinnamic acid der 2, 13 Kaempferol 3-O-rhamnoside, 14 flavonoid der, 15 Rhamnetin der, 16 p-OH-cinnamic acid der 3, 17 Galangin der 1, 18 Galangin der 2, 19 Apigenin, 20 Methyl-naringenin, 21 Acacetin. der = derivative of mentioned compound

About $42 \%$ of the pollen grains in the lingonberry honey samples originated from Vaccinium species, mainly V. vitis-idaea (Fig. 2) and V. myrtillus origin (Fig. 3) (Table 4). Some samples also contained pollen grains of $V$. oxycoccus (Fig. 4). Other pollen grains typical of the samples of this honey came from Rosaceae, Salix, Trifolium and Apiaceae species.

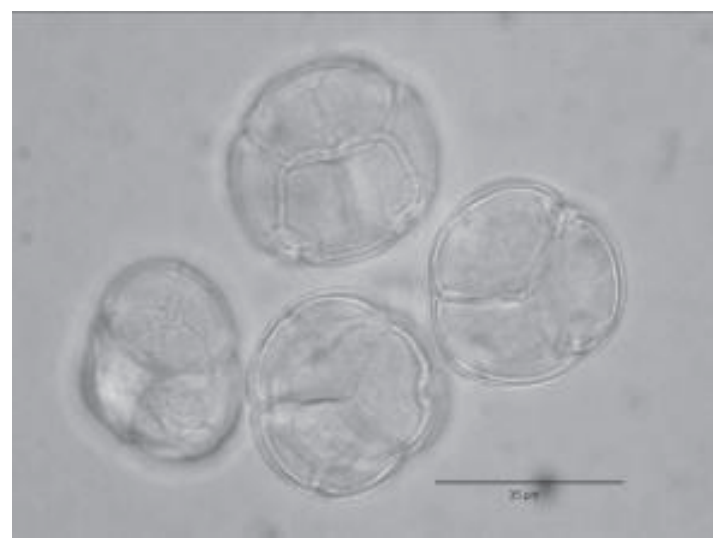

Fig. 2. Pollen grain of Vaccinium vitis-idaea. 


\section{AGRICULTURAL AND FOOD SCIENCE}

A. Salonen \& R. Julkunen-Tiitto (2012) 21: 159-170

Table 3. Identified phenolic compounds of lingonberry and mire honeys.

\begin{tabular}{|c|c|c|c|c|c|}
\hline & & Lingonberry & & & \\
\hline Phenolic compound & & honey & Mire honey & Identificati & \\
\hline$\mu \mathrm{g} \mathrm{g}^{-1}$ & $\mathrm{t}_{\mathrm{R}}$ & Mean $\pm \mathrm{SE}$ & Mean $\pm \mathrm{SE}$ & spectrum & MS-ions \\
\hline Cinnamic acid der $1^{*}$ & 3.1 & $0.22 \pm 0.05$ & & $\mathrm{x}$ & \\
\hline Protocatechuic acid* & 4.0 & trace & $0.46 \pm 0.10$ & $x$ & $155(\mathrm{M}+\mathrm{H})$ \\
\hline Cinnamic acid der $2 *$ & 7.5 & $1.46 \pm 0.22$ & $0.56 \pm 0.10$ & $\mathrm{x}$ & \\
\hline Vanillic acid* & 8.5 & $3.08 \pm 0.59$ & $1.11 \pm 0.12$ & $\mathrm{x}$ & $169(\mathrm{M}+\mathrm{H}), 191(\mathrm{M}+\mathrm{Na})$ \\
\hline Chlorogenic acid der** & 10.4 & - & trace & $x$ & 455 \\
\hline$p$-OH-cinnamic acid der $1 * *$ & 13.3 & $1.54 \pm 0.43$ & $2.52 \pm 0.22$ & $\mathrm{x}$ & $165(\mathrm{M}+\mathrm{H})$ \\
\hline Benzoic acid* & 13.5 & $2.28 \pm 0.20$ & $2.70 \pm 0.52$ & $\mathrm{x}$ & $123(\mathrm{M}+\mathrm{H}), 145(\mathrm{M}+\mathrm{Na})$ \\
\hline Ferulic acid** & 14.4 & $1.17 \pm 0.28$ & $1.20 \pm 0.12$ & $\mathrm{x}$ & $195(\mathrm{M}+\mathrm{H}), 217(\mathrm{M}+\mathrm{Na})$ \\
\hline Tetragalloylglucose $* *$ & 16.2 & trace & trace & $x$ & \\
\hline Benzoic acid der** & 17.1 & - & $0.48 \pm 0.07$ & $\mathrm{x}$ & 303 \\
\hline Cinnamic acid der $3^{*}$ & 22.4 & $0.49 \pm 0.13$ & $0.59 \pm 0.05$ & $\mathrm{x}$ & \\
\hline$p$-OH-cinnamicacid der $2 * *$ & 23.9 & $0.85 \pm 0.15$ & - & $\mathrm{x}$ & \\
\hline Kaempferol 3-O-rhamnoside** & 27.4 & trace & trace & $x$ & $455(\mathrm{M}+\mathrm{H})$ \\
\hline flavonoid der** & 28.1 & trace & - & $x$ & \\
\hline Rhamnetin der** & 29.1 & - & trace & $\mathrm{x}$ & \\
\hline$p$-OH-cinnamicacid der $3 * *$ & 31.3 & trace & - & $\mathrm{x}$ & \\
\hline Galangin der $1^{*}$ & 33.2 & $0.21 \pm 0.04$ & $0.23 \pm 0.06$ & $\mathrm{x}$ & $271(\mathrm{M}+\mathrm{H})$ \\
\hline Galangin der $2^{*}$ & 33.8 & trace & - & $\mathrm{x}$ & $271(\mathrm{M}+\mathrm{H})$ \\
\hline Apigenin $* *$ & 34.4 & trace & - & $\mathrm{x}$ & $271(\mathrm{M}+\mathrm{H})$ \\
\hline Methyl-naringenin** & 38.3 & $0.36 \pm 0.01$ & $0.40 \pm 0.10$ & $x$ & $287(\mathrm{M}+\mathrm{H})$ \\
\hline Acacetin $^{* *}$ & 44.1 & trace & - & $\mathrm{x}$ & \\
\hline Total amount of phenolic compo & nds $\mu \mathrm{g} \mathrm{g}^{-1}$ & 11.22 & 10.06 & & \\
\hline Amount of phenolic acids $\mu \mathrm{g} \mathrm{g}^{-1}$ & & 11.08 & 9.61 & & \\
\hline Amount of flavonoids $\mu \mathrm{g} \mathrm{g}^{-1}$ & & 0.57 & 0.63 & & \\
\hline Ratio: phenolic acids/ flavonoids & & 19.49 & 15.25 & & \\
\hline
\end{tabular}

trace $=$ very low amount in one sample, $\mathrm{tR}=$ retention time, $\mathrm{SE}=$ standard error of the mean, der $=$ derivative of mentioned compound, * monitored at $220 \mathrm{~nm}, * *$ monitored at $320 \mathrm{~nm}$.

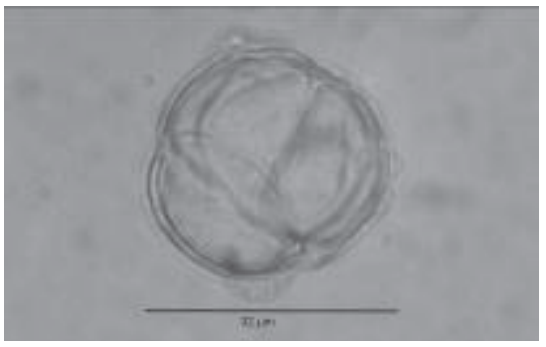

Fig. 3. Pollen grain of Vaccinium myrtillus.

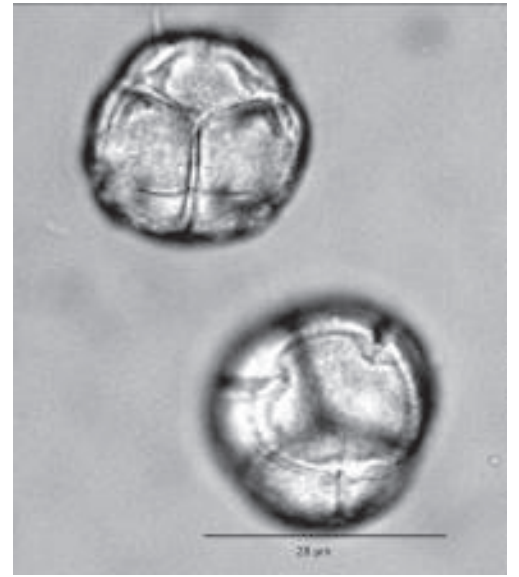

Fig. 4. Pollen grain of Vaccinium oxycoccos. 


\section{AGRICULTURAL AND FOOD SCIENCE}

A. Salonen \& R. Julkunen-Tiitto (2012) 21: 159-170

Table 4. Melissopalynological analysis of lingonberry and mire honeys (expressed as the percentage of a pollen group out of all counted pollen grains).

\begin{tabular}{llll}
\hline Pollen group & $\begin{array}{l}\text { Lingonberry honey } \\
\text { Mean } \pm \text { SE }\end{array}$ & $\begin{array}{l}\text { Mire honey } \\
\text { Mean } \pm \text { SE }\end{array}$ & $\begin{array}{l}\text { Finnish polyfloral } \\
\text { honey } \%^{*}\end{array}$ \\
\hline $\mathrm{n}$ & 7 & 8 & 734 \\
\hline Apiaceae & $7 \pm 3$ & $7 \pm 2$ & 3 \\
Brassicaceae & 0 & 0 & 32.0 \\
Epilobium & present & present & present \\
Geranium & present & present & present \\
Menyanthes trifoliata & present & $2 \pm 2$ & present \\
Rosaceae & $18 \pm 3$ & $10 \pm 2$ & 30 \\
Rubus chamaemorus & present & $2 \pm 2$ & present \\
Salix & $13 \pm 4$ & $25 \pm 6$ & 8 \\
Trifolium & $7 \pm 2$ & $3 \pm 3$ & 15 \\
Vaccinium & $43 \pm 7$ & $45 \pm 7$ & 3 \\
Others & $12 \pm 6$ & $7 \pm 2$ & 9 \\
\hline
\end{tabular}

$\mathrm{n}=$ number of samples, $\mathrm{SE}=$ standard error of the mean, * Reference: Salonen et al. (2011).

\section{Mire honey}

The electrical conductivity of the mire honey was over $1.0 \mathrm{mS} \mathrm{cm}^{-1}$, the water content was low, the invertase activity value high and the $\mathrm{pH}$ is around 4.9 (Table 1 ).

In sensory analyses mire honey showed medium colour intensity and a reddish colour tone. The intensity of the odour was medium and it was described as "straw, dry hay, mint, solvent, fresh, orange blossom". Tasting assessments varied greatly: sweetness, acidity, bitterness, aroma and persistence or after-taste were evaluated with all the scores (0-3). Aroma was described as "refreshing, apricot, solvent, aniseed, eucalyptus, dates prunes and fruit".

All the mire honey samples contained six disaccharides: sucrose, turanose, maltose or trehalose (peaks overlapping), isomaltose and two unknown disaccharides (Table 2). Of the oligosaccharides, mire honey samples contained raffinose in trace amounts, as well as erlose, melezitose or both (peaks overlapping).

Only fourteen phenolic compounds could be identified in mire honey samples (Fig. 1): four cinnamic acid derivatives and flavonoids, benzoic, vanillic and protocatechuic acids, chlorogenic acid derivative, benzoic acid derivative and tetragalloylglucose. The total amount of flavonoids was very low $\left(0.63 \mu \mathrm{g} \mathrm{g}{ }^{-1}\right)$, and the 


\section{AGRICULTURAL AND FOOD SCIENCE}

A. Salonen \& R. Julkunen-Tiitto (2012) 21: 159-170

ratio of phenolic acids to flavonoids was 15.25 (Table 3). Benzoic acid and p-OH-cinnamic acid derivative 1 were found in the highest amounts. Mire honey had no unifloral specific phenolic compounds.

Melissopalynological analyses indicated that $44 \%$ of the pollen grains in the mire honey came from the Vaccinium family, mostly from species such as V. myrtillus (Fig. 3) and V. vitis-idaea (Fig. 2) and only few from $V$. uliginosum (Fig. 5) and $V$. oxycoccos (Fig. 4) (Table 3), which grow on mires. The amount of pollen grains from the Salix species was more abundant than that in Finnish polyfloral honey. Other pollen grains typical of this unifloral honey came from Rosaceae, Apiaceae and Trifolium species, which are also common in Finnish polyfloral honey samples and from other plant species growing on mire biotopes, $R$. chamaemorus (Fig. 6) and M. trifoliata (Fig. 7) (Table 3).
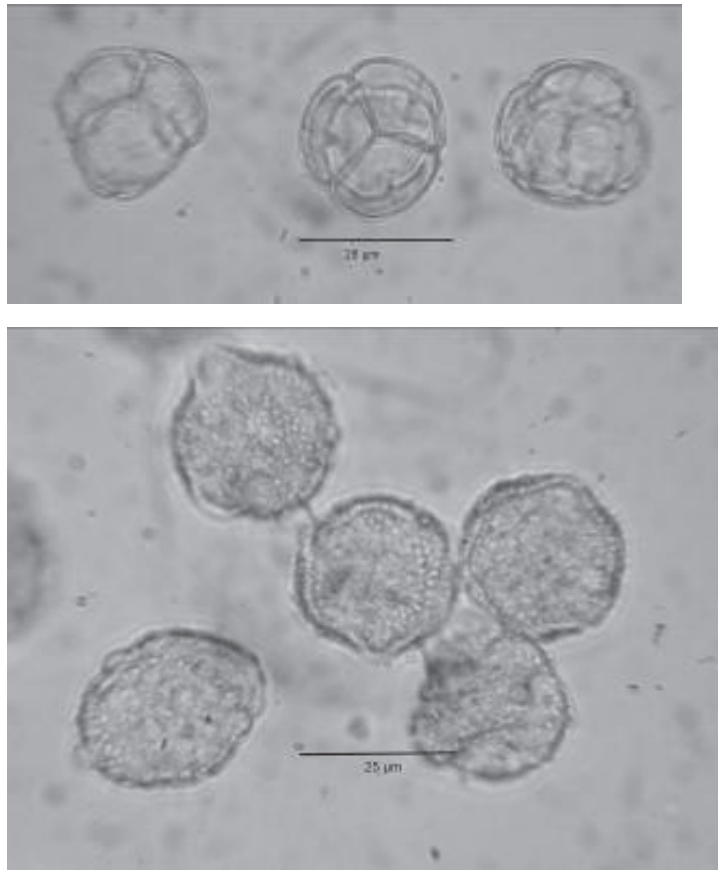

Fig. 6. Pollen grain of Rubus chamaemorus.
Fig. 5. Pollen grain of Vaccinium uliginosum.

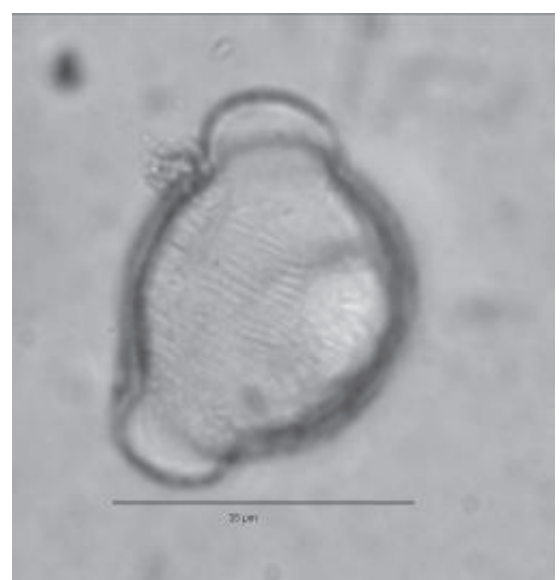

Fig. 7. Pollen grain of Menyanthes trifoliata.

\section{Discussion}

\section{Lingonberry honey}

The average electrical conductivity of Finnish polyfloral honeys is under $0.3 \mathrm{mS} \mathrm{cm}^{-1}$ (Table 1). The high electrical conductivity of the lingonberry honey $\left(0.5 \mathrm{mS} \mathrm{cm}^{-1}\right)$ and the special organoleptical properties can be used as indicators when separating lingonberry honey from other Finnish honey varieties. Lingonberry honey was rich in fructose which means that the ratio of fructose/glucose was 1.48 and the ratio of glucose/water was 1.68 . These ratios indicate that lingonberry honey granulates slowly.

In lingonberry honey pollen grains of Vaccinium species were found in highest amount (Tabel 3). Pollen 


\section{AGRICULTURAL AND FOOD SCIENCE}

A. Salonen \& R. Julkunen-Tiitto (2012) 21: 159-170

grains of Salix and Apiaceae species were also found in higher amounts than in Finnish unifloral honeys (Salonen et al. 2009), since these species flower at the same time as lingonberries. In addition, pollen grains of Geranium. sylvaticum, which is a common plant in Finnish nature (Lampinen and Lahti 2011) and flowers at the same time as lingonberries, were expected to be found in lingonberry honey in greater amounts than in Finnish unifloral or polyfloral honeys. However, the total amount of pollen grains of $G$. sylvaticum was very low, although it has been observed (personal communication with beekeepers) that bees visit G. sylvaticum very diligently. The size of G. sylvaticum pollen grains (Fig. 8) is huge, and it is known that bees are able to filter large pollen grains out of the nectar easily as they fly from the forage flowers to the hive (Bryant and Jones 2001). This means that pollen of G. sylvaticum may be highly under-represented in honey samples. We know very little of the importance of $G$. sylvaticum as a potential nectar plant. This issue needs to be further researched in the near future.

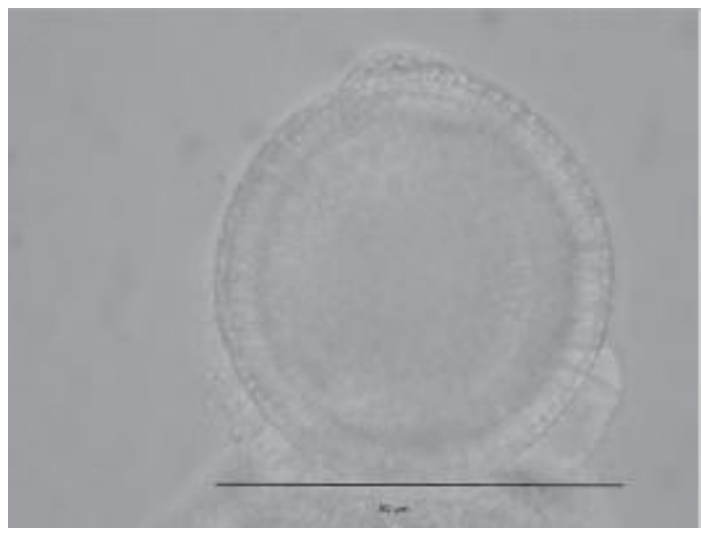

Fig. 8. Pollen grain of Geranium sylvaticum.

From the phenolic acids in lingonberry honey, vanillic acid was found in highest amount. Its amount was notably higher than in mire or in other Finnish unifloral honey (Salonen et al. 2011). Vanillic acid has also been found in Bulgarian (Dimitrova et al. 2007) unifloral honeys. Phenolic compounds typical for lingonberry honey samples were cinnamic acid derivative $1, \mathrm{p}-\mathrm{OH}$-cinnamic acid derivative 2 and acacetin. These compounds were not found either in Finnish unifloral raspberry or in fireweed honey samples (Salonen et al. 2011), while acacetin can be found in acacia honey (Marghitas et al. 2010).

Lingonberry honey is collected from mid-June till the end of June. Lingonberries bloom every year, but it seems that nectar production varies greatly from year to year and that the yield of the lingonberry honey depends very much on weather conditions in June. Thanks to its special toffee odour and taste and its reddish colour, lingonberry honey can easily be recognised even from the honeycombs in the hive.

\section{Mire honey}

The electrical conductivity of the mire honey (Table 1) was the highest (over $1.0 \mathrm{mS} \mathrm{cm}^{-1}$ ) when compared with polyfloral or unifloral honeys collected in Finland (Salonen et al. 2011). According to EU's honey directive, the electrical conductivity of a honey should not exceed the limit of $0.8 \mathrm{mS} \mathrm{cm}^{-1}$, unless the honey is derived from honeydew. In the melissopalynological analysis we found very few honeydew marks, proving that mire honey was nectar honey. For this reason mire honey should be added to the list of exceptions in honey directive, where unifloral nectar honeys having electrical conductivity over 0.8 are 


\section{AGRICULTURAL AND FOOD SCIENCE}

A. Salonen \& R. Julkunen-Tiitto (2012) 21: 159-170

mentioned (European Commission 2002). Interestingly, the pH of mire honey was very high, although in a mire biotope the substrate is acidic (Kaakinen et al. 2008). Like lingonberry honey, mire honey was rich in fructose and it granulates slowly, as well.

Generally, when compared with other Finnish poly- and unifloral honeys, mire honey has a very peculiar and strong odour and taste, resembling, for example, chestnut, lime or heather honeys (Persano Oddo and Piro 2004), and it is highly valued in Finland. Based on its organoleptic characteristics, mire honey samples win the category of unifloral honeys in the Finnish honey competition almost every year.

Mire honey had no unifloral specific phenolic compounds. In addition, the low amount of phenolic compounds was rather surprising. It was expected that mire honey could contain abundant amounts of phenolics that might contribute to some extent to the organoleptic characteristics of the honey. Vanillic acid is a phenolic of this kind; however, its content was low, as much as three times lower when compared with lingonberry honey, but nevertheless six times higher than in Finnish raspberry and fireweed honeys (Salonen et al. 2011).

To collect mire honey, beekeepers transfer their hives from Central Finland to mire areas, mainly to Lapland and Northern Ostrobothnia at the end of May. Melissopalynological analyses (Table 4) indicated that $44 \%$ of the pollen grains in the mire honey came from $V$. myrtillus, $V$. vitis-idaea, $V$. uliginosum and $V$. oxycoccos, which grow on mires. The amount of pollen grains from the Salix species was more abundant than that in Finnish polyfloral or lingonberry honey samples because mire honey is collected early in the summer, when Salix species are the most important food plants for bees, and some Salix species flower on mires in June, as well. The amounts of pollen grains from plant species typical for mire biotopes, $R$. chamaemorus and M. trifoliate were low.

The denomination of unifloral honey may be difficult to establish. In the EU Council Directive relating to honey it is stated that "In trade the simple product name "honey" is used and it can be supplemented by the information of the floral, vegetable, regional, territorial or topographical origin" (European Commission 2002). Mire honey is commercially named "Cloudberry honey" or "Honey from cloudberry mire", because cloudberry ( $R$. chamaemorus) is widespread in mire biotypes and a very highly valued berry in Finland. However, there is no research on the amount of nectar secretion of cloudberry flowers in Finland. Cloudberry is a dioecious plant species and there seems to be no agreement of the amount of nectar in female or male plant individuals (Brown and McNeil 2009). According to our melissopalynological analyses, the amount of $R$. chamaemorus pollen grains was very moderate in cloudberry honey, so it is unlikely that $R$. chamaemorus would be at least the main source of nectar for mire honey.

Pollen grains of $M$. trifoliata are generally found in mire honey samples in low amounts. This plant commonly grows on Finnish mires (Lampinen and Lahti 2011), but there is no information about its nectar production. Secondary metabolites, such as phenolic acids and flavonoids, could be used as markers of the floral origin of the honey (Tomas-Barberan et al. 2001). M. trifoliata leaves contain many phenolic compounds, such as iridoids and secoiridoids, secologanate, dihydrofoliamenthin, quercetin-glycoside and kaempferol-glycoside, in a fairly high concentration (Martz et al. 2009). In our study these phenolic compounds were not found in the mire honey samples. Nevertheless, pollen grains of $M$. trifoliate in mire honey proved that bees visit the plant. 


\section{AGRICULTURAL AND FOOD SCIENCE}

A. Salonen \& R. Julkunen-Tiitto (2012) 21: 159-170

\section{Conclusions}

This study discribes the physico-chemical composition and phenolic content of two different types of Finnish unifloral honey. These unique honeys differ in terms of their odour, flavour, taste, electrical conductivity and also their sugar and phenolic content. According to our results, the best tools in order to discriminate these honeys from other Finnish poly- and unifloral honeys are the value of electrical conductivity, special taste and odour and the phenolic content of lingonberry honey. Although these two unifloral honeys are not widely produced, they are of high interest. Their collection demands more work, which affects the production cost and therefore their price is higher compared to other Finnish unifloral honeys. They are a very welcome addition to the fairly modest Finnish unifloral honey selection. In the near future more research will be conducted on such issues as their floral origin, volatile compounds and antibacterial properties, as well as their influence on human health.

\section{Acknowledgements}

We should like to thank the Finnish Beekeepers Association and Ms. Tarja Ollikka for supplying us with the honey samples for this work and the photos for this article, and Ms. Mervi Kupari for technical assistance. The study was partly financed by project 1997 financed via the Centre for Economic Development, Transport and the environment.

\section{References}

Ahti, T., Hämet-Ahti, L. \& Jalas, J. 1968. Vegetation zones and their sections in northwestern Europe. Annales Botanici Fennici 5: 169-211.

Bogdanov, S., Jurendic, T., Sieber, R. \& Gallmann, P. 2008. Honey for Nutrition and Health: a Review. American Journal of the College of Nutrition 27: 677-689.

Bogdanov, S. 2009. Harmonised methods of the International Honey Commission. Cited 16 January 2012. Available on the Internet: http://www.bee-hexagon.net/files/file/fileE/IHCPapers/IHC-methods_2009.pdf.

Brown, A.O. \& Mcneil, J.N. 2009. Pollination ecology of the high latitude, dioecious cloudberry (Rubus chamaemorus; Rosaceae). American Journal of Botany 96: 1096-1107.

Bryant, V.M. \& Jones, G.D. 2001. The R-value of honey: Pollen coefficients. Palynology 25: 11-28.

Dimitrova, B., Gevrenova, R. \& Anklam, E. 2007. Analysis of phenolic acids in honeys of different floral origin by solidphase extraction and high-performance liquid chromatography. Phytochemical Analysis 18: 24-32.

European Commission 2002. Council Directive 2001/110/EC concerning honey. Official Journal of European Communities Jan 12th 2002. L10/47-52.

Fukuda, M., Kobayashi, K., Hirono, Y., Miyagawa, M., Ishida, T., Ejiogu, E.C., Sawai, M., Pinkerton, K.E. \& Takeuchi, M. 2011. Jungle Honey Enhances Immune Function and Antitumor Acivity. Evidence-Based Complementary and Alternative Medicine Article ID 908743, 8 p.

Julkunen-Tiitto, R. \& Sorsa, S. 2001. Testing the drying methods for willow flavonoids, tannins and salicylates. Journal of Chemical Ecology 27: 779-789.

Kaakinen, E., Aapala, K. \& Kokko, A. 2008. The Diversity and Current Condition of Finnish Mires. In: Korhonen, R., Korpela, L. \& Sarkkola, S. (eds.). Finland - Fenland: Research and sustainable utilisation of mires and peat. The Finnish Peatland Society. Helsinki, Maahenki Ltd. p. 34-52.

Keski-Saari, S., Pusenius, J. \& Julkunen-Tiitto, R. 2005. Phenolic compounds in seedlings of Betula pubescens and B. pendula are affected by enhanced UV-B radiation and different nitrogen regimes during early ontogeny. Global Change Biology 11: 1180-1194.

Lampinen, R. \& Lahti, T. 2011. Kasviatlas 2010. Helsingin Yliopisto, Luonnontieteellinen keskusmuseo, Kasvimuseo, 


\section{AGRICULTURAL AND FOOD SCIENCE}

A. Salonen \& R. Julkunen-Tiitto (2012) 21: 159-170

Helsinki. Cited 16 January 2012. Available on the Internet : http://www.luomus.fi/kasviatlas.

Louveaux, J., Maurizio, A. \& Vorwohl, G. 1978. Methods of melissopalynology. Bee World 59: 139-157.

Marghitas, L.A., Dezmirean, D.S., Pocol, C.B., Ilea, M., Bobis, O. \& Gergen, I. 2010. The development of a biochemical profile of acacia honey by identifying biochemical determinants of its quality. Notulae Botanicae Horti Agrobotanici Cluj-Napoca 38: 84-90.

Martz, F., Turunen, M., Julkunen-Tiitto, R., Lakkala, K. \& Sutinen, M-L. 2009. Effect of the temperature and the exclusion of UVB radiation on the phenolics and iridoids in Menyanthes trifoliata L. leaves in the subarctic. Environmental Pollution 157: 3471-3478.

Persano Oddo, L. \& Piro, R. 2004. Main European unifloral honeys: descriptive sheets. Apidologie 35: S38-S81.

Piana, M L., Persano Oddo, L., Bentabol, A., Bruneau, E., Bogdanov, S. \& GuyotDeclerck, C. 2004. Sensory analysis applied to honey: state of the art. Apidologie 35: S26-S37.

Salonen, A., Ollikka, T., Grönlund, E., Ruottinen, L. \& Julkunen-Tiitto, R. 2009. Pollen analyses of honey from Finland. Grana 48: 281-289.

Salonen, A., Hiltunen, J. \& Julkunen-Tiitto, R. 2011. Composition of Unique Unifloral Honeys from the Boreal Coniferous Forest Zone: Fireweed and Raspberry Honey. Journal of ApiProduct and ApiMedical Science 3: 128-136.

Tomas-Barberan, F.A., Martos, I., Ferreres, F., Radovic, B.S. \& Anklam, E. 2001. HPLC flavonoid profiles as markers for the botanical origin of European unifloral honeys. Journal of the Science of Food and Agriculture 81: 485-496.

Vasander, H., Tuittila, E-S., Lode, E., Lundin, L., Ilomets, M., Sallantaus, T., Heikkilä, R., Pitkänen, M-L. \& Laine, J. 2003. Status and restoration of peatlands in northern Europe. Wetlands Ecology 11: 51-63.

Varis, A-L., Helenius, J. \& Koivulehto, K. 1983. Composition and properties of Finnish honey and their dependence of the season, region, bee race and botanical origin. Journal of theSscientific Agricultural Society of Finland 55: 451-463.

White, J.W. 2005. Honey. In: Graham, J.M. (ed.). The hive and the honey bee. Dadant \& sons, Hamilton, Illinois, p. 869-927. 